\title{
Air Pollution and Daily Mortality in Inchon, Korea
}

\begin{abstract}
The association between total daily mortality and air pollution was investigated for a 1-year period (January 1995 to December 1995) in Inchon, Korea. The purpose of this study was to evaluate the relative importance of particulate and gaseous air pollution as predictors of daily mortality. Concentration of total suspended particulates (TSP), inhalable particles ( $\left.\mathrm{PM}_{10}\right)$, and gaseous pollutants, such as sulfur dioxide, nitrogen dioxide, ozone, carbon monoxide, were measured daily during the study period. A generalized additive model was used to regress daily death counts on each air pollutant, controlling for time trend and meteorologic influences such as temperature or relative humidity. Total mortality was found to increase $1.2 \%$ (95\% Cl: 0.2 to $2.2 \%$ ) for each $10 \mu \mathrm{g} / \mathrm{m}^{3}$ increase in 6-day moving average of TSP, and $1.2 \%(95 \% \mathrm{Cl} 0.2$ to $2.1 \%)$ for each $10 \mu \mathrm{g} / \mathrm{m}^{3}$ increase in 5-day moving average of $\mathrm{PM}_{10}$. The association is similar in magnitude to associations between particulate air pollution and mortality found in several other communities in America and Europe. Associations with gaseous pollutants were all statistically insignificant in the generalized additive model. The relative risk of death increased at particulate levels that were well below the current Korean Ambient Air Quality Standard.
\end{abstract}

Key Words: Air pollution; Mortality; Particle size; Gases; Nitrogen dioxide; Ozone; Carbon monoxide

\author{
Yun Chul Hong, Jong Han Leem, Eun Hee Ha ${ }^{\star}$ \\ Department of Prevertive Mecicine, Inha University, \\ College of Medicine, Inchon, Korea \\ *Department of Preventive Medicine, Ewha \\ Womens University, College of Medicine, Secul, \\ Korea \\ Received: 13 August 1998 \\ Accepted: 4 December 1998 \\ Address for correspondence \\ Yun Chul Hong, M.D. \\ Department of Preventive Mecicine, Inha University, \\ College of Medicine, 253 Yonghyur-cong, \\ Nam-gu, Inchon 402-751, Korea \\ Tel : +82.32-890-2860, Fax: $+82.32-890-2859$ \\ E-mail : ychong@dragon.inha.ac.kr \\ *This research was supported by Inha University \\ Research Fund, 1997
}

\section{INTRODUCTION}

The most acute episode occurred in London in 1952, when 4,000 excess deaths were attributed to air pollution. Other acute episodes were reported in Donora in 1948, New York in 1953 and Los Angeles in 1963. Effects were the strongest among populations that are especially vulnerable to stress, including the chronically ill and the elderly. It is difficult to demonstrate the association of increased morbidity and mortality with exposure to air pollution, because of confounders such as age, smoking, genetic susceptibility, socioeconomic status, residential period, racial background, previous respiratory disease and weather condition. However, consistent association has been demonstrated between residential period and increased mortality in the air pollution areas, when the confounders were controlled $(1,2)$. Different prevalence rates of respiratory symptoms between high air pollution areas and low air pollution areas has also been observed $(3,4)$. Increased daily mortality associated with various measures of particulate air pollution has been reported in a number of communities. Daily mortality has been associated with total suspended particulates
(TSP) in Steubenville (5), and Philadelphia (6), and Mexico City (7) and with particulate matter less than $10 \mu \mathrm{m}$ $\left(\mathrm{PM}_{10}\right)$ in Utah Valley (2), Birmingham $(8,9)$, St. Louis and Kingston (10) and Amsterdam (11). Most published reports carried out in the U.S.A. show that particulate matter exhibits the relationship most clearly $(2,5,12$ 16). The relationship appears to continue well below current ambient air quality standards $(17,18)$. In Europe, a series of investigations has been carried out but the results were more diverse in terms of the pollutant with the strongest associations. In most European cases, there was a significant relation between mortality and either $\mathrm{SO}_{2}$ or particulate matter (19-24). The combining effects of dust particles and certain components may have an important role in the damaging process than dust particles only. Different areas have different mixtures of particles. Thus, it is unclear whether the same particles/mortality relationships found in America or Europe would apply equally for Inchon, Korea.

Only a few studies described the association between the present levels of air pollution in Eastern Asia and mortality $(25,26)$. The objective of the present study was to report on the association between daily mortality and 
daily levels of ambient air pollution in Inchon.

\section{MATERIALS AND METHODS}

\section{Mortality data}

Daily deaths for the Inchon area were read from the annual detail mortality tapes of the National Statistical Office for the period of January 1, 1995 to December 31, 1995. The cause-specific categories included in the present analysis were cardiovascular deaths, respiratory deaths and total deaths not due to accidents or violence. The tenth revision International Classification of Diseases (ICD) codes was used to define these categories.

\section{Study area and weather data}

The city of Inchon is located on western side of the Korean peninsula and with a sea on the west and metropolitan Seoul on the east. It is the third largest city in the country. The population of Inchon was 2.2 million as indicated by the 1995 census. It has a four-season climate; low-level temperature inversions are common during the winter months. Data on 24-hr mean temperature and relative humidity were obtained from the Inchon weather station.

\section{Air pollution}

Air pollution data were obtained from the Department of Environmental Engineering, Inha University where the data were routinely audited. Three monitoring sites for 24-hr measurements of air pollution were established by

Table 1. Mean values of variables related to daily mortality in Inchon, Korea

\begin{tabular}{lrrrc}
\hline Variable & $\mathrm{N}$ & Mean & $\mathrm{SD}$ & Range \\
\hline Mortality & & & & \\
$\quad$ Total death/day & 365 & 21.9 & 5.1 & $10-37$ \\
$\quad$ Cardiovascular deaths/day & 365 & 6.8 & 2.8 & $1-18$ \\
$\quad$ Respiratory deaths/day & 365 & 1.2 & 1.1 & $0-6$ \\
Meteorology & & & & \\
$\quad$ Temperature $\left({ }^{\circ} \mathrm{C}\right)$ & 365 & 11.9 & 9.7 & $-7.0-28.0$ \\
$\quad$ Relative humidity (\%) & 365 & 69.2 & 14.8 & $32.1-96.4$ \\
Particulate pollution & & & & \\
$\quad \mathrm{TSP}\left(\mu \mathrm{g} / \mathrm{m}^{3}\right)$ & 343 & 92.1 & 42.7 & $16.7-307.3$ \\
$\mathrm{PM}_{10}\left(\mu \mathrm{g} / \mathrm{m}^{3}\right)$ & 341 & 74.4 & 34.4 & $15.0-213.8$ \\
Gaseous pollution & & & & \\
$\mathrm{SO}_{2}(\mathrm{ppb})$ & 358 & 22.6 & 8.7 & $7.2-52.8$ \\
$\mathrm{NO}_{2}(\mathrm{ppb})$ & 358 & 23.0 & 9.4 & $5.2-58.1$ \\
$\mathrm{O}_{3}(\mathrm{ppb})$ & 358 & 12.9 & 5.2 & $1.9-33.7$ \\
$\mathrm{CO}^{(\mathrm{ppm})}$ & 346 & 1.7 & 0.8 & $0.3-5.1$ \\
\hline
\end{tabular}

the Department of Environment. Two TSP monitoring sites of the three were: (1) the Pupyong monitor, located near the industrialized area; and (2) the Kuwol monitor, located in residental area. One additional $\mathrm{PM}_{10}$ monitoring site was established later in the Sungwei area which is an old residential area. TSP levels at the Pupyong and Kuwol sites were 85.02 and $102.56 \mu \mathrm{g} / \mathrm{m}^{3}$, respectively, and they correlated significantly with each other $(\mathrm{r}=0.56$, $p<0.01) . \mathrm{PM}_{10}$ levels at the Sungwei site were relatively high and equaled $74.40 \mu \mathrm{g} / \mathrm{m}^{3}$ and correlated well with the mean of two TSP levels $(\mathrm{r}=0.80, p<0.01)$. Simultaneous monitoring of sulfur dioxide $\left(\mathrm{SO}_{2}\right)$, nitrogen dioxide $\left(\mathrm{NO}_{2}\right)$, ozone $\left(\mathrm{O}_{3}\right)$, and carbon monoxide $(\mathrm{CO})$ was conducted at the three sites (Table 1). Concentrations of these pollutants were measured hourly during the period, and 24-hr averages were constructed among measurement sites.

\section{Statistical analysis}

The association between daily mortality and air pollutants was analyzed with a generalized additive model using S-plus statistical software (version 4.0). Mortality is classically modeled as a Poisson process, which can generally be described as a process that generates independent and rare occurrences. Daily mortality was fit to the generalized additive model, which included Loess function of time trend (number of days since the start of study), temperature and relative humidity. Among the variables, relative humidity explained the variation in mortality significantly $(p<0.05)$ while time trend and temperature did not. However, we included these three variables in the basic model. Once this model was established, the additional effect of each air pollutant or two pollutants in predicting daily mortality was evaluated separately. Air pollutants may affect mortality with some lags, and the appropriate average time for exposure may exceed $24 \mathrm{hr}$; therefore, concurrent exposure and multiple-day moving averages (up to 6 days) were considered. In these models, as in a classic Poisson model, we assume $\log [\mathrm{E}(\mathrm{Y})]=\mathrm{X} \beta$, where $\mathrm{E}(\mathrm{Y})$ denotes the expected value of daily deaths; $\mathrm{X}$ is the matrix of covariates; and $\beta$ is the vector of the estimated regression coefficients (27, 28). The relative risk estimates are given by the exponential of the $\beta$ coefficients. The estimated percentage that increased with deaths attributed to air pollution based on this model is calculated as follows: $\left(\varepsilon^{\beta \chi}-1\right) 100$, where $\chi$ is the mean pollution concentration and $\beta$ is the regression coefficient for the pollutant.

\section{RESULTS}

The distribution of mortality, meteorologic measures, 
Table 2. Correlations between meteorologic and air pollutant variables and daily mortality

\begin{tabular}{lccccccc}
\hline \multirow{2}{*}{ Variables } & \multicolumn{7}{c}{ Multiple-day moving average } \\
\cline { 2 - 7 } & Current exposure & $0-1$ days & $0-2$ days & $0-3$ days & $0-4$ days & $0-5$ days & $0-6$ days \\
\hline Temperature & $-0.19^{\dagger}$ & $-0.19^{\dagger}$ & $-0.20^{\dagger}$ & $-0.20^{\dagger}$ & $-0.21^{\dagger}$ & $-0.21^{\dagger}$ & $-0.21^{\dagger}$ \\
Relative humidity & -0.04 & -0.01 & $-0.12^{\star}$ & $-0.14^{\dagger}$ & $-0.17^{\dagger}$ & $-0.18^{\dagger}$ & $-0.19^{\dagger}$ \\
$\mathrm{TSP}$ & 0.07 & $0.14^{\dagger}$ & $0.15^{\dagger}$ & $0.18^{\dagger}$ & $0.20^{\dagger}$ & $0.20^{\dagger}$ & $0.17^{\dagger}$ \\
$\mathrm{PM}_{10}$ & 0.05 & $0.13^{\star}$ & $0.15^{\dagger}$ & $0.16^{\dagger}$ & $0.18^{\dagger}$ & $0.17^{\dagger}$ & $0.16^{\dagger}$ \\
$\mathrm{SO}_{2}$ & 0.08 & $0.13^{\star}$ & $0.14^{\dagger}$ & $0.16^{\dagger}$ & $0.16^{\dagger}$ & $0.16^{\dagger}$ & $0.16^{\dagger}$ \\
$\mathrm{NO}_{2}$ & $0.12^{\star}$ & $0.18^{\dagger}$ & $0.19^{\dagger}$ & $0.21^{\dagger}$ & $0.21^{\dagger}$ & $0.20^{\dagger}$ & $0.17^{\dagger}$ \\
$\mathrm{O}_{3}$ & $-0.14^{\dagger}$ & $-0.17^{\dagger}$ & $-0.18^{\dagger}$ & $-0.19^{\dagger}$ & $-0.18^{\dagger}$ & $-0.18^{\dagger}$ & $-0.18^{\dagger}$ \\
$\mathrm{CO}$ & 0.07 & $0.11^{\star}$ & $0.11^{\star}$ & $0.12^{\star}$ & $0.12^{\star}$ & $0.11^{\star}$ & $0.11^{\star}$ \\
\hline
\end{tabular}

${ }^{\star} p<0.05,{ }^{\dagger} p<0.01$

and air pollution between January 1, 1995 and December 31, 1995 are presented for Inchon (Table 1). TSP exceeded the ambient 24-hr standard of $300 \mu \mathrm{g} / \mathrm{m}^{3}$ on 1 day and $\mathrm{PM}_{10}$ exceeded the ambient 24-hr standard of $150 \mu \mathrm{g} / \mathrm{m}^{3}$ on 10 days. $\mathrm{PM}_{10}$ level was $80.8 \%$ of the mean of two TSP levels, however it decreased to $72.5 \%$ of TSP level in residential areas only. There were no violations of ambient standards for gaseous pollutants.

The Pearson correlation between variables and multiple-day lagged moving averages are presented in Table 2. Correlations between the daily mortality and pollution variables were small but significant. Negative correlation between the daily mortality and $\mathrm{O}_{3}$ was noticeable and there was also a negative correlation between daily mortality and relative humidity. The stronger association with mortality was seen at multiple-day lagged moving averages rather than current exposure, especially strong correlations were at 6-day moving average of TSP and 5-day moving average of other pollutants. Significant correlations were seen between mortality and temperature. Relative humidity was also significantly associated with mortality. Controlling these two meteorologic variables and time trend in the model of regression resulted in a better explanation of influence of individual pollutants to mortality (Fig. 1).

The relationship between particulate pollution and mortality was complicated by the fact that periods with highest particulate matter pollution occurred during winter months, and a higher incidence of death may be at least partially due to cold winter weather. We controlled for this with a generalized additive model, which included time trend and weather variables as described above. In one pollutant model which included one pollutant in the basic model controlling for time trend and weather (Table 3), particulate pollutants were significant predictors of daily mortality. An increase in 6-day moving aver-

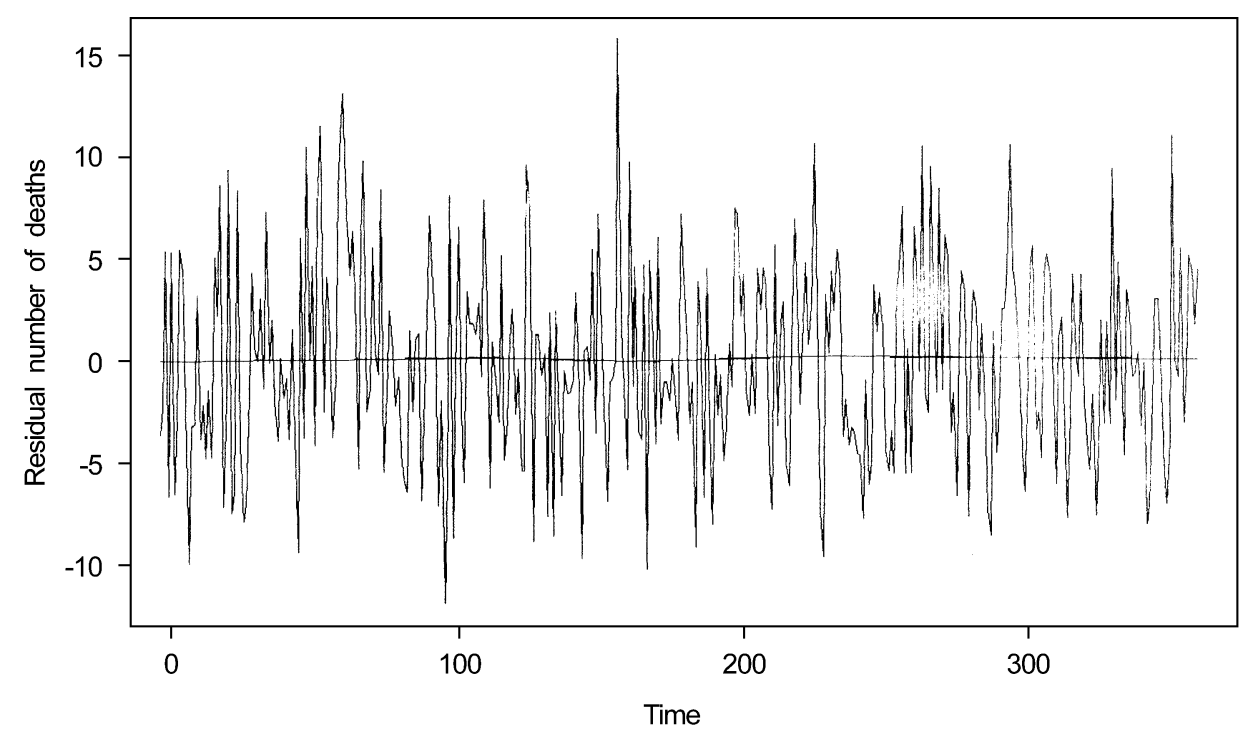

Fig. 1. Plot of the residual number of deaths each day controlling for time trend and weather variables. After filtering, no time trend was observed. The line was fitted with the locally weighted regression (Loess) method. 
Table 3. Comparison of one pollutant model regression with multiple-day moving average of pollution on daily mortality controlling for time trend and weather variables

\begin{tabular}{lcc}
\hline Pollutant & Relative risk & 95\% Cl \\
\hline 6-day moving average of $\mathrm{TSP}^{*}$ & 1.012 & $1.002-1.022$ \\
5-day moving average of $\mathrm{PM}_{10}{ }^{*}$ & 1.012 & $1.002-1.021$ \\
5-day moving average of $\mathrm{SO}_{2}{ }^{\dagger}$ & 1.007 & $0.956-1.062$ \\
5-day moving average of $\mathrm{NO}_{2}{ }^{\dagger}$ & 1.038 & $0.996-1.081$ \\
5-day moving average of $\mathrm{O}_{3}{ }^{\dagger}$ & 0.943 & $0.864-1.029$ \\
5-day moving average of $\mathrm{CO}^{\dagger}$ & 0.993 & $0.950-1.037$ \\
\hline
\end{tabular}

*relative risk for an increase of $10 \mu \mathrm{g} / \mathrm{m}^{3}$

${ }^{t}$ relative risk for an increase of $10 \mathrm{ppb}$

${ }^{\dagger}$ relative risk for an increase of $1 \mathrm{ppm}$

age of TSP, equal to $10 \mu \mathrm{g} / \mathrm{m}^{3}$, was associated with an increase in relative risk of mortality to $1.2 \%$. The proportion of total deaths attributed to TSP during this period would equal to $11.7 \%$. An increase in 5-day moving average of $\mathrm{PM}_{10}$, equal to $10 \mu \mathrm{g} / \mathrm{m}^{3}$, was associated with an increase in relative risk of mortality to $1.2 \%$. The proportion of total deaths attributed to $\mathrm{PM}_{10}$ during this period would be equalled to 9.3\%. Gaseous pollutants were not associated significantly in the above model. In two pollutant models of $\mathrm{PM}_{10}$ and each gaseous pollutant, $\mathrm{PM}_{10}$ was significantly associated with daily mortality except in the $\mathrm{PM}_{10}$ and $\mathrm{NO}_{2}$ model. In two pollutant models of TSP and each gaseous pollutant, TSP was also significantly associated with daily mortality except in the TSP and $\mathrm{NO}_{2}$ model.

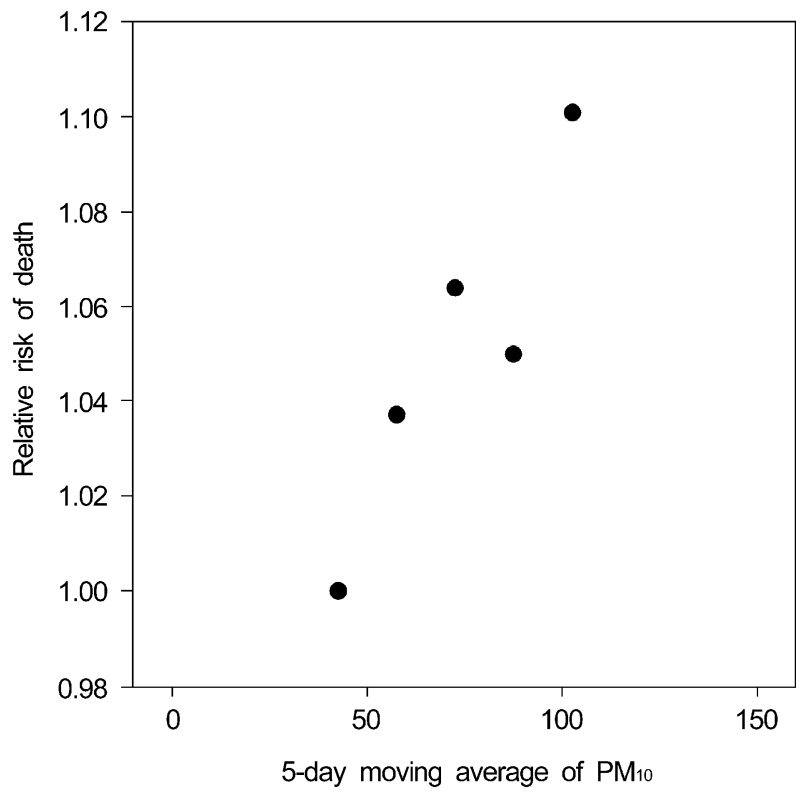

Fig. 2. Relative risk of mortality for quintiles of 5-day moving average of $\mathrm{PM}_{10}$ after controlling for time trend and weather variables
Table 4. Comparison of one pollutant model regression with multiple-day moving average of pollution on daily cardiovascular mortality controlling for time trend and weather variables

\begin{tabular}{lcc}
\hline Pollutant & Relative risk & 95\% Cl \\
\hline 6-day moving average of $\mathrm{TSP}^{*}$ & 1.020 & $1.002-1.038$ \\
5-day moving average of $\mathrm{PM}_{10}{ }^{*}$ & 1.014 & $0.996-1.031$ \\
5-day moving average of $\mathrm{SO}_{2}{ }^{\dagger}$ & 1.028 & $0.937-1.129$ \\
5-day moving average of $\mathrm{NO}_{2}{ }^{\dagger}$ & 1.041 & $0.968-1.120$ \\
5-day moving average of $\mathrm{O}_{3}{ }^{\dagger}$ & 0.928 & $0.793-1.087$ \\
5-day moving average of $\mathrm{CO}^{\dagger}$ & 0.965 & $0.892-1.044$ \\
\hline
\end{tabular}

*relative risk for an increase of $10 \mu \mathrm{g} / \mathrm{m}^{3}$

${ }^{t}$ relative risk for an increase of $10 \mathrm{ppb}$

${ }^{\dagger}$ relative risk for an increase of $1 \mathrm{ppm}$

To show the dose-response relationship between particulate matter and daily mortality, the 5-day moving average of $\mathrm{PM}_{10}$ levels was replaced in the model with dummy variables for quintiles of the $\mathrm{PM}_{10}$ levels. Fig. 2 shows the relative risk of mortality by 5-day moving average of $\mathrm{PM}_{10}$, with the risk in the lowest quintile taken as one after controlling for time trend and weather variables. Excess mortality risk is clearly evident in the upper range of $\mathrm{PM}_{10}$ levels and there is a dose-response relationship.

Regression results were also obtained for respiratory and cardiovascular death. No significant pollution slopes were obtained in respiratory death and this result was expected due to the very small number of respiratory daily deaths. In one pollutant model for cardiovascular mortality, the association of TSP with mortality remained significant (Table 4).

\section{DISCUSSION}

This study documents a strong association between mortality and particulate pollution. A relationship between deaths per day and TSP was observed in some studies that used data from Steubenville (5) and Philadelphia (6) in U.S.A. and Mexico City (7). An increase in TSP equal to $100 \mu \mathrm{g} / \mathrm{m}^{3}$ was associated with an estimated increase in deaths per day of $4 \%, 7 \%$, and $6 \%$, respectively. Daily deaths were also associated with $\mathrm{PM}_{10}$ in St. Louis and Kingston in U.S.A. (10) and Birmingham in U.K. (9), and Amsterdam in the Netherlands (11). An increase in $\mathrm{PM}_{10}$ of $100 \mu \mathrm{g} / \mathrm{m}^{3}$ was estimated to increase in mortality by 16.2 and $17.4 \%$, respectively in St. Louis and Kingston. The effect of $100 \mu \mathrm{g} / \mathrm{m}^{3}$ in $\mathrm{PM}_{10}$ was estimated to represent a $11 \%$ and $6 \%$ increase in mortality in Birmingham and Amsterdam, respectively. In the Utah County study, an increase in $\mathrm{PM}_{10}$ of $100 \mu \mathrm{g} / \mathrm{m}^{3}$ was estimated to increase mortality by 
approximately $16 \%$ (2). Mortality increased with particulate pollution, and the pollution effect was observable even at relatively low levels of particulate pollution. The increases in daily mortality in Inchon associated with a $100 \mu \mathrm{g} / \mathrm{m}^{3}$ increase in TSP and $\mathrm{PM}_{10}$ were $12.8 \%$ and $13.0 \%$, respectively. The values are in the upper range of those found in above studies. The reason for this high risk in Inchon is not clear. It is possible that higher concentrations of particulate matters make the risk higher than in lower concentration area. Another possibility for this high risk is that the chemical composition of particulates in Inchon is different from other areas.

High particulate pollution concentrations in Inchon occur during cold winter weather. There are substantial differences in the coincidental weather patterns that accompany particulate exposure in different locations in the world. However the observed associations are very similar between particulate pollution and mortality. It is unlikely that confounding weather effects are the source of the apparent pollution effects. Sources and levels of ambient air pollution as well as population characteristics and habits vary widely among America, Europe and Korea. The results of this study suggest that these differences do not largely influence the relationship.

The associations between particulate pollution and mortality are also observed when time trend and weather variables are accounted for. Given the coherency of the observed associations between particulate pollution and mortality across different geographic locations, the association reported herein indicates that particulate pollution is an important contributor to premature death. The association is observed at pollution levels well below Korean ambient air quality standards (24-hr standard of TSP, $300 \mu \mathrm{g} / \mathrm{m}^{3}$; 24-hr standard of $\left.\mathrm{PM}_{10}, 150 \mu \mathrm{g} / \mathrm{m}^{3}\right)$. From multiple studies with similar finding and effect sizes, and the manifestation of a dose-response relationship, the relationships appear to be causal. However, the mechanism for association between daily mortality and particulate air pollution is not obvious. Some studies provide evidence that $\mathrm{PM}_{10}$ has free radical activity and causes lung inflammation $(29,30)$. Heavy metals and polycyclic aromatic hydrocarbons $(\mathrm{PAH})$ in particulate pollution may have harmful effects $(31,32)$, although the specific mechanism is not clear yet.

$\mathrm{NO}_{2}, \mathrm{SO}_{2}$, and $\mathrm{CO}$ are gaseous pollutants released mainly from motor vehicle and combustion sources. Our analysis showed that gaseous pollutants were not significantly associated with daily mortality and the association of gases remained insignificant in two pollutants model controlling particulate pollutant. This result was similar with previous reports which described insignificant association between mortality and gases, when particulate pollutants were included in the model. It was well known that $\mathrm{NO}_{2}$ and $\mathrm{SO}_{2}$ are converted to sulfates and nitrates, thus contributing to the fine particles. That makes the individual effect of the gaseous pollutants more difficult to explain. Despite of inhibition of oxygen carrying capacity and the possibility of increasing susceptibility of severely compromised patient, $\mathrm{CO}$ was not remarkably associated with mortality.

Epidemiological findings show that $\mathrm{O}_{3}$ exposure is associated with transient adverse respiratory effects in healthy people, as well as in people with preexisting respiratory disease (34). In this study, $\mathrm{O}_{3}$ exposure was insignificantly negatively and associated with mortality. The negatively directed association was not changed even when analysis was confined to summer, and this result was at least partly related to low ozone concentrations in Inchon. Because $\mathrm{O}_{3}$ is a secondary pollutant and sensitive to methods of weather control, more investigations are needed to study the adverse health effect of $\mathrm{O}_{3}$ in diverse locations of different ozone concentrations and weather conditions. The few deaths due to respiratory and cardiovascular causes may have limited our ability to detect small pollution associations. However, deaths associated with pollution exposures should not necessarily be classified as respiratory or cardiovascular. A variety of advanced disease states might predispose individuals to increased susceptibility to premature death due to air pollution exposure. It is important to emphasize that, although statistically significant associations have been detected among mortality and particulates, one can never conclude with complete confidence that such associations are causal based on results from an observational study. Future studies should be directed at providing insight into the mechanisms underlying a possible causal relationship between particulate exposures and mortality.

\section{ACKNOWLEDGEMENT}

We wish to thank Suk-yon Cho for the air pollution data and Douglas Dockery for his review of this manuscript.

\section{REFERENCES}

1. Lave LB, Seskin EP. Air pollution and human health. Science 1970; 169: 723-8.

2. Pope III CA, Schwartz J, Ransom MR. Daily mortality and $P M_{10}$ pollution in Utah valley. Arch Environ Health 1992; 47 : 211-7.

3. Ware JH, Ferris BG, Dockery DW, Spengler JD, Stram DO, Speizer FE. Effects of ambient sulfur dioxides and suspended particles on respiratory health of preadolescent. Am Rev 
Respir Dis 1986; 133: 834-42.

4. Saric M, Fugus M, Hrustic O. Effects of urban air pollution on school-age children. Arch Environ Health 1981; 36: 101-8.

5. Schwartz J, Dockery DW. Particulate air pollution and daily mortality in Steubenville, Ohio. Am J Epidemiol 1992; 135: 12-9.

6. Schwartz J, Dockery DW. Increased mortality in Philadelphia associated with daily air pollution concentrations. Am Rev Respir Dis 1992; 145: 600-4.

7. Borja-Aburto VH, Loomis DP, Bangdiwala SI, Shy CM, Rascon-Pacheco RA. Ozone, suspended particulates, and daily mortality in Mexico City. Am J Epidemiol 1997; 145: 258-68.

8. Schwartz J. Air pollution and daily mortality in Birmingham, Alabama. Am J Epidemiol 1993; 137: 1136-47.

9. Wordley J, Walters S, Ayres JG. Short term variations in hospital admissions and mortality and particulate air pollution. Occup Environ Med 1997; 54: 108-16.

10. Dockery DW, Schwartz J, Spengler JD. Air pollution and daily mortality: associations with particulates and acid aerosols. Environ Res 1992; 59: 362-73.

11. Verhoeff AP, Hoek G, Schwartz J, van Wijnen JH. Air pollution and daily mortality in Amsterdam. Epidemiology 1996; 7: 225-30.

12. Schwartz J. Total suspended particulate matter and daily mortality in Cincinnati, Ohio. Environ Health Perspect 1994; 102: 186-9.

13. Kinney PL, Ozkaynak H. Associations of daily mortality and air pollution in Los Angeles County. Environ Res 1991; 54 : 99-120.

14. Schwartz J. Particulate air pollution and daily mortality in Detroit. Environ Res 1991; 56: 204-13.

15. Fairley D. The relationship of daily mortality to suspended particulates in Santa Clara County, 1980-86. Environ Health Perspect 1990; 89: 159-68.

16. Schwartz J, Dockery DW, Neas LM. Is daily mortality associated with fine particles? J Air Waste Manage Assoc 1996; 46: $927-39$.

17. Ostro BD. A search for a threshold in the relationship of air pollution to mortality: a reanalysis of data on London winters. Environ Health Perspect 1984; 58: 397-9.

18. Environmental Protection Agency. Air quality criteria for particulate matter and sulfur oxides. vol 3. Research triangle park. NC: Environmental Protection Agency, 1982 (EPA publication no. 600/8-82-092c).

19. Schwartz J , Marcus A. Mortality and air pollution in London: a time series analysis. Am J Epidemiol. 1990; 131: 185-94.

20. Zmirou D, Barumandzadeh T, Balducci F, Ritter P, Laham G,
Ghilardi JP. Short term effects of air pollution on mortality in the city of Lyon, France, 1985-90. J Epidemiol Comm Health 1996; 50(suppl 1): S30-5.

21. Anderson HR, Ponce de Leon A, Bland JM, Bower JS, Strachan DP. Air pollution and daily mortality in London: 1987-92. $\mathrm{Br}$ Med J 1996; 312: 665-9.

22. Shimmel $\mathrm{H}$, Murawski TJ. The relation of air pollution to mortality. J Occup Med 1976; 18: 316.

23. Katsouyanni K, Hatzakis A, Kakandidi A, Trichopoulos D. Short-term effects of atmospheric pollution on mrtality in Athens. Arch Hellen Med 1990; 7: 126-32.

24. Ballester F, Corella D, Perez-Hoyos S, Hervas A. Air pollution and mortality in Valencia, Spain: a study using the APHEA methodology. J Epidemiol Comm Health 1996; 50: 527-33.

25. Lee J, Lee S, Shin D, Chung Y. Air particulate matters and daily mortality in Ulsan, Korea. Korean J Prev Med 1998; 31 : $82-90$.

26. Xu X, Gao J, Dockery DW, Chen Y. Air pollution and daily mortality in residential areas of Beijing, China. Arch Environ Health 1994; 49: 216-22.

27. Zeger SL, Liang KY. Longitudinal data analysis for discrete and continuous outcomes. Biometrika 1986; 42: 121-30.

28. Liang KY, Zeger SL. Longitudinal data analysis using generalized linear models. Biometrika 1986; 73: 13-22.

29. Li XY, Gilmour PS, Donaldson K, MacNee W. In vivo and in vitro proinflammatory effects of particulate air pollution. Environ Health Perspect 1997; 105(Suppl 5): 1279-83.

30. Carter JD, Ghio AJ, Samet JM, Devilin RB. Cytokine production by human airway epithelial cells after exposure to an air pollution particle is metal-dependent. Toxicol Appl Pharmacol 1997; 146: 180-8.

31. Bagnoli P, Carrozzino S, Pisani B, Righini F. Chemical characterization of the PM10/PM2.5 fraction of airborne particulate matter in the urban atmosphere. J Environ Pathol Toxicol Oncol 1997; 16: 219-25.

32. Morrozzi G, Conti R, Pampanella L, Marchetti MC, Bucci P, Scardazza F, Manenti R, Sebastiani B. Chemical analysis and biological activity of airborne particulate matter. $J$ Environ Pathol Toxicol Oncol 1997; 16: 133-46.

33. Moolgavkar SH, Luebeck EG. A critical review of the evidence on particulate air pollution and mortality. Epidemiology 1996; 7: 420-8.

34. Lippmann M. Health effects of tropospheric ozone: review of recent research findings and their implications to ambient air quality standards. J Exp Anal Environ Epidemiol 1993; 3: 103-29. 